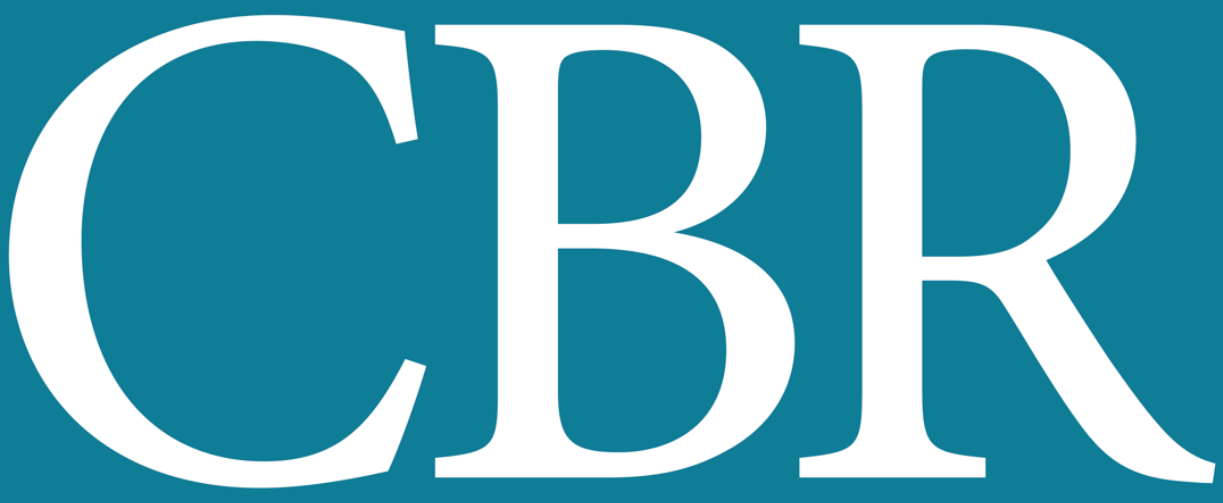

INTERNATIONAL JOURNAL OF CANCER AND BIOMEDICAL RESEARCH

https://jcbr.journals.ekb.eg

Editor-in-chief

Prof. Mohamed Labib Salem, PhD

Early onset gastric cancer in Egyptian patients: Is it really a different clinical entity?

Ahmed Ramez, Maha El-Zaafarany, Hayam Ghazy, Basel Refky, Amany Hassan and Manar Hamed 


\section{Welcome letter from Editor-in-Chief}

Welcome to the Int J Cancer and Biomedical Research (IJCBR)!

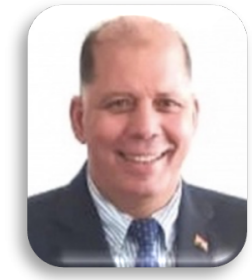

It is with great pleasure that I write this editorial to welcome you to the IJCBR. This journal provides a platform for publication of original and reviews research articles, short communications, letter to editor, thesis abstract, conference report, and case studies. These types of publication are directed at the interface of the fields of cancer and biomedical research.

The IJCBR relies on a distinguished expert of the Advisory and Editorial Board Members from the top international league covering in depth the related topics. They timely review all manuscripts and maintain highest standards of quality and scientific methodology and ethical concepts. Meanwhile, we take all possible means to keep the time of the publication process as short as possible.

I take this chance to welcome your contributions to the IJCBR and have every expectation that it will soon become one of the most respected journals in both the fields of cancer and biomedical research.

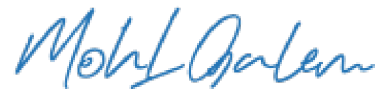

Mohamed L. Salem,

Editor in Chief 


\title{
Early onset gastric cancer in Egyptian patients: Is it really a different clinical entity?
}

\author{
Ahmed Ramez ${ }^{1}$, Maha El-Zaafarany ${ }^{1}$, Hayam Ghazy ${ }^{1}$, Basel Refky ${ }^{2}$, Amany Hassan ${ }^{3}$ and Manar Hamed ${ }^{1}$ \\ ${ }^{1}$ Department of Medical Oncology, Mansoura University, Mansoura, Egypt \\ ${ }^{2}$ Department of Surgical Oncology, Mansoura University, Mansoura, Egypt \\ ${ }^{3}$ Department of Pathology, Mansoura University, Mansoura, Egypt
}

\section{IIII}

Background: Little is known about characteristics of young patients with gastric carcinoma (GC) in Egypt. Aim: The purpose of this study was to define the clinicopathological features and survival of young GC patients in our population. Patients and Methods: We retrospectively analyzed data of $197 \mathrm{GC}$ patients who were treated at our institution from 2011 to 2016. The clinicopathological characteristics and survival were compared between 61 young ( $\leq 45$ years) and 136 older (>45 years) GC patients. We also studied variables impacting survival of younger patients. Results: The proportion of females, positive family history, and poorly differentiated tumors were significantly higher in young patients. Younger group showed significantly longer interval between symptoms and diagnosis (all P $<0.05$ ). The mean overall survival (OS) of young patients was lower compared to older patients ( 10.7 vs. 18.7 months, respectively; $P=0.06$ ). Multivariate analyses revealed that distant metastasis and CA19-9 were independent factors for reduced survival in younger patients. Conclusion: We conclude that clinicopathological characteristics of GC are different between young and old patients. Aggressive tumor biology and a significant diagnostic delay may have contributed to worse survival in younger patients.

Keywords: Gastric carcinoma; young age; clinicopathological features; prognosis

Editor-in-Chief: Prof. M.L. Salem, PhD - Article DOI: 10.21608/jcbr.2020.48678.1089
ARTICLE INFO

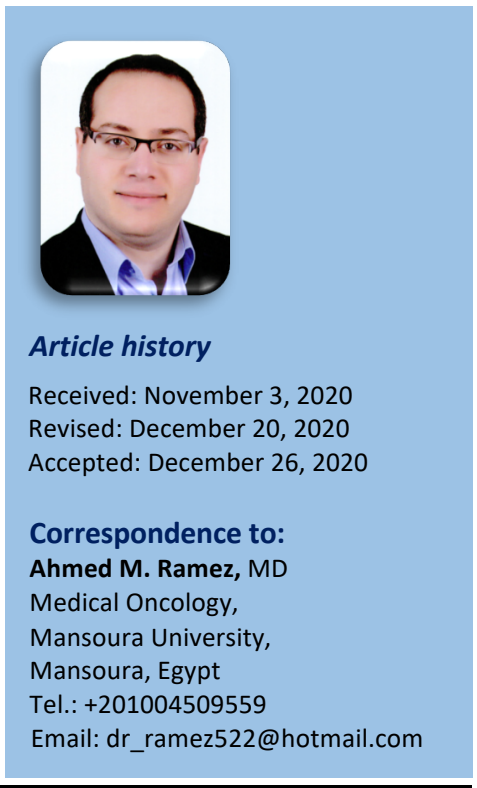

\section{INTRODUCTION}

Gastric carcinoma (GC) represents the fifth most common and the third most deadly malignancy worldwide based on data from GLOBOCAN 2018 [Bray et al., 2018]. Classically, $\mathrm{GC}$ is considered a disease of elderly with the mean age at diagnosis ranging from 50 to 60 years [Piazuelo and Correa, 2013]. Although younger people are less affected by GC, it has been recognized that the incidence rate of $\mathrm{GC}$ in young patients shows an increasing trend over the past few decades [Kuller, 1999; Anderson et al., 2010; Al-Refaie et al., 2011]. Studies have reported the percentage of patients with GC under 40 years of age ranging from $2 \%$ to $16 \%$ [Wang et al., 2014].

The data on whether clinicopathological features and prognosis of GC in young patients differ from that in older population have been controversial. Some reports have suggested that young patients have adverse features and worse prognosis compared with older subjects, while other studies reported equivalent or even better prognosis among GC patients of young age [Santoro et al., 2007; Saito et al., 2012; Hsieh et al., 2012; Takatsu et al., 2015]. These conflicting results reflect the fact that clinical characteristics of younger group were analyzed on the basis of a heterogeneous population of patients with respect to races and different definitions of young age across studies [Kunisaki et al., 2006; Kong et al., 2012; Isobe et al., 2013]. Another issue is the variation in access to care between different countries that may have a significant impact on survival. Because of the lack of data on the characteristics of young GC patients in our geographical area, we performed a retrospective cohort study to assess the clinicopathological features and 
survival of GC patients aged 45 years old or younger compared with the more typical GC population of patients $>45$ years old.

\section{PATIENTS AND METHODS}

This is a retrospective observational study of all patients diagnosed with GC and treated at Department of Medical Oncology, Mansoura University, Egypt from 2011 to 2016. In this study, the data of one hundred and ninetyseven GC patients were collected and examined. Of these, 61 patients aged 45 years old or younger were classified as the young group and 136 patients aged over 45 years old were classified as the old group. The reason behind this grouping was to maintain consistency with prior studies, including largest population-based study, that have categorized younger gastric cancer patients as those below cut off age of 40 to 50 years [Al-Refaie et al., 2011; Hsieh et al., 2012; Dai et al., 2017].

Clinical and pathological characteristics including gender, family history, presenting symptoms, tumor shape, tumor size, tumor location, histological type, histological grade, depth of invasion, nodal involvement, extent of cancer spread, and tumor markers were compared between both groups. Data on therapies applied in metastatic cases were also obtained. Metastatic cases were followed for response to therapy by CT scans every 3 months using RECIST 1.1 criteria. Clinicopathological data and follow-up data were retrieved from the patients' electronic records. Survival was measured in months from date of diagnosis of $\mathrm{GC}$ to date of death. For alive patients, overall survival was censored on December 31, 2019. This study was approved by the Ethical Committee of Mansoura University, Mansoura, Egypt (IRB code number: MS/17.12.90).

\section{Statistical Analysis}

Statistical analysis was done using SPSS program (SPSS, Inc, Chicago, IL) version 21. Chi square or Fisher's exact tests were used to compare groups. The Kaplan-Meier method was used to calculate the OS rates. The log-rank test was used for univariate analysis of the relationship between clinicopathological variables and survival. Variables that showed significance in the univariate analysis were included in the multivariate analysis using the Cox proportional hazard model. P-values of $<0.05$ were considered significant.

\section{RESULTS}

In our analysis, the mean ages of the young and old groups were about 37 and 58 years old, respectively. There was a significant difference in the proportion of females between both groups. In the young group, females represented $63.9 \%$ of patients compared to only $38.2 \%$ in the old group $(P<0.001)$. For the young group, the percentage of patients giving positive family history for cancer was higher than that in old group ( $5 \%$ vs. $0.7 \%, P=0.03$ ). The proportion of patients testing positive for hepatitis C virus (HCV) antibodies was significantly higher in older patients than in young patients ( $33.1 \%$ vs. $14.8 \%, \mathrm{P}<0.001$ ).

The main presenting symptom in young patients was vomiting $(49.2 \%)$ while older patients manifested mainly with epigastric pain (43.3\%). Regarding tumor morphology, it was more common for GC in young patients to present as stomach wall thickening (44.3\%) compared to gastric mass in older patients (55.9\%). The latent period between symptoms and diagnosis was significantly higher in young patients compared to old patients (median: 6 vs. 2 months, $\mathrm{P}=0.05$ ). Regarding histological grade, the percentage of poorly differentiated tumors in young group was higher than that in old group $(65.6 \%$ vs. $39 \%, P=0.004)$. There were no statistically significant differences in tumor location, tumor size or pathological type. Other clinical and demographic data are shown in Table 1. Although it was not statistically significant, the rate of curative resection was numerically higher in younger patients $(52.4 \%$ vs. $46.3 \%$ ). Table 2 illustrates the extent of cancer spread in both groups at presentation. For the operated cases, no difference was found in depth of invasion or lymph node metastasis between the two groups. Similarly, there was no difference in the rate of metastatic disease at presentation or site of metastases between both groups. However, for younger patients who were metastatic at presentation, there was a trend toward multiple sites of metastases compared with older group (39.4\% vs. $29.5 \%, \mathrm{P}$ $=0.08$ ). 
Treatment of metastatic cases according to age group is summarized in Table 3 . The percentage of patients who did not undergo any active treatment due to poor performance was significantly lower in the young group $(9.1 \%$ vs. $21.1 \%, P=0.04)$. Similarly, more patients in the young group were fit enough to proceed to third line therapy in progressive cases $(18.2 \%$ vs. $5.6 \%, P=0.08)$. No difference was found in the rate of duplet vs. triplet therapy applied in both groups. Also, no differences were observed in the response rate to first line therapy or the rate of palliative surgery between both groups.

Regarding survival, the mean overall survival (OS) in young patients was 10.7 months ( $\mathrm{Cl} 7.8$ -13.6) which was much lower than that of older patients (18.7 months, $\mathrm{Cl} 14.5$ - 22.8). The difference showed marginal significance $(P=$ 0.06). One-year survival rates were $28.6 \%$ for the young group vs. $32.4 \%$ for the old group. Three- year survival rates were $8.2 \%$ and $20.1 \%$, respectively. The survival curves of the two groups are shown in Figure 1. To explore the variables impacting prognosis in young GC patients, univariate and multivariate analyses were performed. Univariate analysis showed that depth of invasion ( $T$ stage), lymph node involvement ( $\mathrm{N}$ stage), distant metastases and CA19-9 level were prognostic factors (Table 4). Multivariate analysis demonstrated that only distant metastases and elevated CA19-9 level were independent negative prognostic factors of young GC patients. conducted mainly in Asian countries [Saito et al., 2012; Hsieh et al., 2012; Wang et al., 2014; Takatsu et al., 2015], while only few, if any, data come from Africa and the Middle East. In addition, data on differing prognosis between younger and older patient groups have not been consistent [Santoro et al., 2007; Al-Refaie et al., 2011; Bautista et al., 2014]. That is why we decided to look into the characteristics and prognosis of this group of patients in our population. In the current study, we noted a significantly higher female prevalence among young group compared with older subjects. This was consistent with several other studies [Wang et al., 201; Prochorov et al., 2015; Liu et al., 2016].

Reasons behind such discrepancy are still unknown however hormonal differences may be implicated. Another explanation may be the higher estrogen receptors expression and intracytoplasmic estradiol in young patients with GC [Wakui et al., 2008]. Moreover, a study suggested that the higher female prevalence among young patients may be associated with recent pregnancies [Kath et al., 2000]. However, we did not find female gender to be a prognostic variable in this group of patients. Nevertheless, the evidence connecting gender to GC prognosis remains controversial, and more research is required to confirm whether gender impacts the prognosis of younger patients or not.

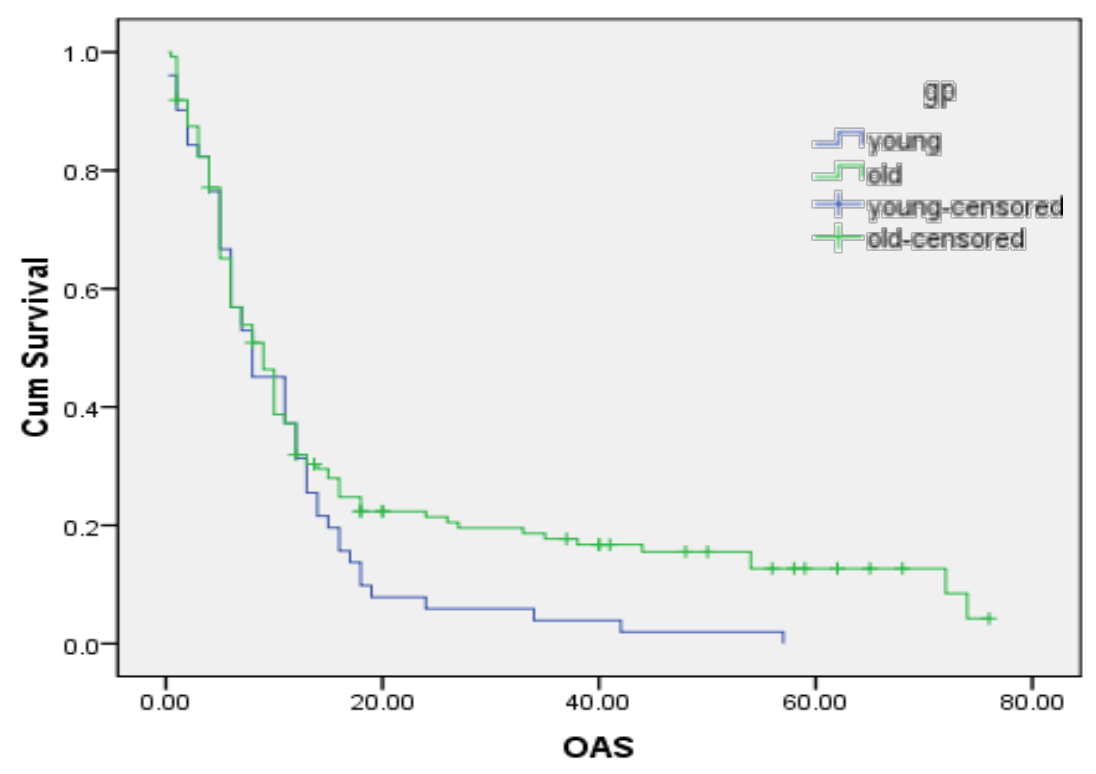

Figure 1. Kaplan Meier curve for OS in young and old group of patients. 
Table 1. Demographic and clinicopathological characteristics of both groups

\begin{tabular}{|c|c|c|c|}
\hline \multirow{2}{*}{ Parameter } & \multicolumn{2}{|c|}{ Age group } & \multirow{2}{*}{$P$ value } \\
\hline & Young ( $N=61$ ) & Old $(N=136)$ & \\
\hline Age in years: (Mean $\pm S D)$ & $37.2 \pm 6.5$ & $58.6 \pm 7.9$ & $<0.001^{*}$ \\
\hline \multicolumn{4}{|l|}{ Gender: No (\%) } \\
\hline Male & $22(36.1)$ & $84(61.8)$ & \multirow{2}{*}{$0.001^{*}$} \\
\hline Female & $39(63.9)$ & $52(38.2)$ & \\
\hline Positive Family History: No (\%) & $3(5)$ & $1(0.7)$ & $0.03^{*}$ \\
\hline \multicolumn{4}{|l|}{ Positive for viral markers: No (\%) } \\
\hline $\mathrm{HCV}$ & $9(14.8)$ & $45(33.1)$ & \multirow[t]{2}{*}{$0.03 *$} \\
\hline HBV & $1(1.6)$ & $0(0)$ & \\
\hline \multicolumn{4}{|l|}{ Presenting Symptoms: No (\%) } \\
\hline Epigastic pain & $15(24.6)$ & $59(43.3)$ & \multirow{5}{*}{$0.003 *$} \\
\hline Hematemsis and melena & $9(14.8)$ & $28(20.6)$ & \\
\hline Vomiting & $30(49.2)$ & $39(28.7)$ & \\
\hline Abdominal enlargement & $5(8.2)$ & $2(1.5)$ & \\
\hline Anemia \& Cachexia & $2(3.2)$ & $8(5.9)$ & \\
\hline $\begin{array}{l}\text { Interval between symptoms and diagnosis } \\
\text { (months): median (range) }\end{array}$ & $6(1-12)$ & $2(1-6)$ & $0.05^{*}$ \\
\hline \multicolumn{4}{|l|}{ Site: No (\%) } \\
\hline Pylorus \& Antrum & $30(49.1)$ & $70(51.4)$ & \multirow{4}{*}{0.4} \\
\hline Body & $20(32.8)$ & $39(28.6)$ & \\
\hline Fundus & $4(6.6)$ & $18(13.4)$ & \\
\hline Undetermined & $7(11.5)$ & $9(6.6)$ & \\
\hline \multicolumn{4}{|l|}{ Shape: No (\%) } \\
\hline Mass & $23(37.7)$ & $76(55.9)$ & \multirow{3}{*}{$0.04 *$} \\
\hline Ulcer & $11(18.0)$ & $21(15.4)$ & \\
\hline Thickening & $27(44.3)$ & $39(28.7)$ & \\
\hline Size (cm): median (range) & $5(2-12)$ & $4(1-9)$ & 0.3 \\
\hline \multicolumn{4}{|l|}{ Pathology: No (\%) } \\
\hline Adenocarcinoma & $34(55.7)$ & $87(64)$ & \multirow[t]{2}{*}{0.2} \\
\hline Signet cell carcinoma & $27(44.3)$ & $49(36)$ & \\
\hline \multicolumn{4}{|l|}{ Grade: No (\%) } \\
\hline Well differentiated & $1(1.6)$ & $10(7.4)$ & \multirow{4}{*}{$0.004^{*}$} \\
\hline Moderately differentiated & $10(16.4)$ & $43(31.6)$ & \\
\hline Poorly/undifferentiated & $40(65.6)$ & $53(39)$ & \\
\hline Unknown grade & $10(16.4)$ & $30(22)$ & \\
\hline \multicolumn{4}{|l|}{ Tumor markers: median (IQ range) } \\
\hline CA 19-9 & $12(2188)$ & 14 (709) & 0.4 \\
\hline CEA & $2(82)$ & $2(58)$ & 0.5 \\
\hline CA 125 & $277(356)$ & 74 (279) & 0.9 \\
\hline
\end{tabular}

*P value is statistically significant

\section{DISCUSSION}

Most research investigating the impact of young age at diagnosis on GC outcome have been Not surprisingly, a higher prevalence of positive family history has been observed in our study among younger patients with $\mathrm{GC}$, a finding that we see in other reports [Bautista et al., 2014]. A possible explanation is that in young patients, the development of GC is more likely a result of genetic predisposition. That is why clinicians should pay more attention when a positive family history of cancer exists in a young patient who presents with suspicious symptoms and signs.

In our study, we found that the proportion of young patients who were seropositive for $\mathrm{HCV}$ was significantly lower than older patients (14.8\% vs. $33.1 \%, P=0.03)$. Limited data exist about the association of HCV with GC. A recent Taiwanese study concluded that HCV infection, 
Table 2. Extent of cancer spread for operated and non-operated cases among both groups

\begin{tabular}{|l|c|c|c|}
\hline \multirow{2}{*}{ Parameter No (\%) } & \multicolumn{2}{|c|}{ Age group } & \multirow{2}{*}{ P value } \\
\cline { 2 - 3 } & Young & Old & \\
\hline Rate of curative resection: & $32(52.4)$ & $63(46.3)$ & 0.1 \\
\hline Depth of invasion: & & & 0.3 \\
T1 & $1(3.1)$ & $2(3.2)$ & \\
T2 & $13(40.6)$ & $27(42.9)$ & \\
T3 & $12(37.5)$ & $26(41.2)$ & \\
T4 & $6(18.8)$ & $8(12.7)$ & \\
\hline Nodal involvement: & & & 0.1 \\
N0 & $8(25)$ & $17(27)$ & \\
N1 & $9(28.1)$ & $20(31.7)$ & \\
N2 & $4(12.5)$ & $16(25.4)$ & \\
N3 & $11(34.4)$ & $10(15.9)$ & \\
\hline Metastatic at presentation: & $33(54.1)$ & $71(52.2)$ & 0.7 \\
\hline Site of Metastasis: & & & 0.08 \\
Abdomen (ovary or peritoneal deposits & $17(51.5)$ & $43(60.6)$ & \\
\hline $\begin{array}{l}\text { or abdominal lymph nodes) } \\
\text { Liver }\end{array}$ & $3(9.1)$ & $7(9.9)$ & \\
Multiple sites & $13(39.4)$ & $21(29.5)$ & \\
\hline
\end{tabular}

Table 3. Type of therapy in metastatic cases among both groups

\begin{tabular}{|c|c|c|c|}
\hline \multirow{2}{*}{ Type of therapy No (\%) } & \multicolumn{2}{|c|}{ Age group } & \multirow{2}{*}{$P$ value } \\
\hline & Young ( $\mathrm{N}=33$ ) & Old $(N=71)$ & \\
\hline Best supportive care & $3(9.1)$ & $15(21.1)$ & $0.04^{*}$ \\
\hline $\begin{array}{l}\text { First line chemotherapy } \\
\text { Duplet } \\
\text { Triplet }\end{array}$ & $\begin{array}{l}13(42.4) \\
16(48.5)\end{array}$ & $\begin{array}{l}35(49.3) \\
21(29.6)\end{array}$ & 0.5 \\
\hline $\begin{array}{l}\text { Response to first line chemotherapy } \\
\text { Regressive/Stationary } \\
\text { Progressive }\end{array}$ & $\begin{array}{l}18(54.5) \\
15(45.5)\end{array}$ & $\begin{array}{l}43(60.6) \\
28(39.4)\end{array}$ & 0.9 \\
\hline $\begin{array}{l}\text { Multiple lines of chemotherapy: } \\
2 \text { lines } \\
\geq 3 \text { lines }\end{array}$ & $\begin{array}{c}21(63.6) \\
6(18.2)\end{array}$ & $\begin{array}{c}43(60.5) \\
4(5.6)\end{array}$ & 0.08 \\
\hline Palliative surgery & $9(27.3)$ & 9 (12.7) & 0.07 \\
\hline
\end{tabular}

*P value is statistically significant

Table 4. Univariate and multivariate survival analysis in young patients

\begin{tabular}{|l|c|c|c|c|}
\hline Variable & $\begin{array}{c}\text { Univariate analysis } \\
\text { (P-value) }\end{array}$ & $\begin{array}{c}\text { Multivariate analysis } \\
\text { (P-value) }\end{array}$ & HR & 95\% Cl \\
\hline Gender (female) & 0.7 & - & - & - \\
\hline HCV (positive) & 0.4 & - & - & - \\
\hline Tumor site (pylorus) & 0.08 & - & - & - \\
\hline Tumor size $(\geq 5 \mathrm{~cm})$ & 0.5 & - & - & - \\
\hline Differentiation (poorly) & 0.6 & - & - & - \\
\hline T classification (T3/4) & $0.02^{*}$ & 0.7 & 2.446 & $0.872-9.992$ \\
\hline N classification (N2/3) & $<0.001^{*}$ & 0.6 & 0.865 & $0.109-4.059$ \\
\hline Distant metastasis & $<0.001^{*}$ & $0.018^{*}$ & 4.231 & $1.254-15.872$ \\
\hline Serum CEA (elevated) & 0.1 & - & - & - \\
\hline Serum CA19-9 (elevated) & $0.004^{*}$ & $0.03^{*}$ & 1.983 & $1.239-3.175$ \\
\hline
\end{tabular}

*P value is statistically significant 
male sex and old age were risk factors for GC development and that risk might not be reversed by interferon-based therapy [Chen et al., 2019]. However, it is not clear whether such infection would affect patients' prognosis or not. Further research is needed in this area.

The most frequent symptoms in our study population were vomiting in young patients (49.2\%), and epigastric pain in old patients (43.3\%). We also observed that distal tumor location was the most frequent location among young group, similar to old group, and in agreement with findings in other studies [Liu et al., 2016]. However, with regard to tumor shape, gastric wall thickening was more frequent in young patients in contrast to old group who presented more commonly with gastric mass $(P=0.04)$. This could be correlated with the differing symptomatology between both groups. However, despite that these differences were statistically significant, we believe that clinical manifestations of gastric cancer are not specific for either young or old age, and that medical community should raise the awareness of GC manifestations and prevalence.

Consistent with previous research, we found that younger patients had more poorly/undifferentiated histological grade tumors compared with older subjects who presented more with well/moderately differentiated tumors [Kong et al., 2012; Bautista et al., 2014; Dai et al., 2017]. Some authors attributed these results to predominance of $\mathrm{H}$. pylori infection among young patients compared to older patients and suggested that infection with $\mathrm{H}$. pylori may play a role in development of poorly differentiated tumors in young subjects [Hirahashi et al., 2007]. Unfortunately, the data on the rate of $H$. pylori infection among our patients was not available. On the other hand, there was no significant difference in the rate of signet ring carcinoma between both groups in our study.

Regarding survival of our patients, we found that mean OS was lower in young patients compared to older patients (10.7 vs.18.7 months, $P=0.06$ ). Studies have reported conflicting results regarding survival rates of younger patients with GC. The poorer survival in young patient groups that was reported in some studies was thought to be secondary to aggressive tumor behavior reflected by higher grade and advanced stage at diagnosis [lsobe et al., 2013; Wang et al., 2014]. However, one study found that among those who underwent curative resection, patients $\leq 40$ years had similar 5-year survival rates compared with those $>40$ years [Isobe et al., 2013]. Similarly, other studies found equivalent survival between young and older groups of GC patients [Liu et al., 2016]. In contrast, a large populationbased study found that despite a higher proportion of young patients had higher histological grades and more advanced stage, the 5-year survival rates were better in young patients than in older patients [Al-Refaie et al., 2011]. This was supported by another recent study that found that 5 -year disease-specific survival rate in young patients was significantly higher than that in older group [Dai et al., 2017].

We looked into the interval between symptom recognition by patients and establishing GC diagnosis in both groups. Younger patients showed significantly longer median duration to diagnosis versus older group ( 6 vs. 2 months, P $=0.05$ ). This longer latency before reaching diagnosis may be in part due to younger patients not seeking medical advice early enough as old patients, and in part due to lower clinical suspicion for malignancy by physicians in younger patients compared to older patients. This goes in line with suggestions that a diagnostic delay in young patients may attribute to poorer outcome observed in some studies [Isobe et al., 2013; Wang et al., 2014; Dai et al., 2017]. This finding together with high rate of metastatic disease at presentation (54.1\%), and poor response to first line chemotherapy (45.5\% non-responders), are most likely the reasons why the 3-year survival rate in our patient population is less than $10 \%$ for the young group. Regarding prognostic variable, other studies have suggested various factors that contribute to poorer survival outcomes [Isobe et al., 2013; Liu et al., 2016; Dai et al., 2017]. In this study, distant metastasis and CA19-9 were independent factors in younger patients for reduced survival by multivariate analysis. Our study had few limitations. First, this was a retrospective analysis with relatively 
small patient numbers; a larger well-designed randomized trial should be carried to avoid statistical bias in the future. Second, therapy for metastatic cases was not standardized in our patient population due to variability in access to cancer care in our country (e.g. targeted therapies).

\section{CONCLUSION}

We conclude from our study that the clinical and pathological characteristics of GC are different between young and old patients. We found that survival of young patients was worse than that of older patients. Multiple age-related factors may have contributed to this worse survival, most notably aggressive tumor biology, and a significant diagnostic delay. Thus, despite that young patients are generally healthier and can receive more aggressive treatments compared to older patients, the prognosis for this subset of patients remains poor. Our findings highlight the importance of high clinical suspicion for $\mathrm{GC}$ regardless of age. Also, further investigations of the genetic, and environmental factors behind these age-related differences are warranted. This will better define age-specific patterns of gastric cancer which in turn will help in delivering personalized care for patients in each age group to improve survival rates.

\section{CONFLICTS OF INTEREST}

All authors declared no conflicts of interest.

\section{FUND}

No fund was received for this work.

\section{REFERENCES}

Al-Refaie WB, Hu CY, Pisters PW, Chang GJ. Gastric adenocarcinoma in young patients: a population-based appraisal. Ann Surg Oncol 2011; 18:2800-7.

Anderson WF, Camargo MC, Fraumeni JJ, Correa P, Rosenberg PS, Rabkin CS. Age-specific trends in incidence of noncardia gastric cancer in US adults. JAMA 2010; 303(17):1723-8.

Bautista MC, Jiang SF, Armstrong MA, Postlethwaite D, Li D. Impact of Age on Clinicopathological Features and Survival of Patients with Noncardia Gastric Adenocarcinoma. J Gastric Cancer 2014; 14(4):238-245.

Bray F, Ferlay J, Soerjomataram I, Siegel RL, Torre LA, Jemal A. Global cancer statistics 2018:
GLOBOCAN estimates of incidence and mortality worldwide for 36 cancers in 185 countries. CA: A Cancer Journal for Clinicians 2018; 68:394-424.

Chen CW, Cheng JS, Chen TD, Le PH, Ku HP, Chang $\mathrm{ML}$. The irreversible HCV-associated risk of gastric cancer following interferon-based therapy: a joint study of hospital-based cases and nationwide population-based cohorts. Therap Adv Gastroenterol 2019; 12:1-13.

Dai FX, Jin J, Wang W, Yu SJ, Long ZW, Cai H, et al. Clinicopathological features and prognosis of younger patients with gastric carcinoma. Trans/ Cancer Res 2017;6(2):312-321.

Hirahashi M, Yao T, Matsumoto T, Nishiyama K, Oya $M$, lida $M$, et al. Intramucosal gastric adenocarcinoma of poorly differentiated type in the young is characterized by Helicobacter pylori infection and antral lymphoid hyperplasia. Mod Pathol 2007;20(1):29-34.

Hsieh F, Wang Y, Hsu J, Liu K, Yeh C, Yeh T, et al. Clinicopathological features and prognostic factors of gastric cancer patients aged 40 years or younger. J Surg Oncol 2012;105(3):304-9.

Isobe T, Hashimoto K, Kizaki J, Miyagi M, Aoyagi K, Koufuji K, et al. Characteristics and prognosis of gastric cancer in young patients. Oncol Rep 2013; 30:43-49.

Kath R, Fiehler J, Schneider CP, Hoffken K. Gastric cancer in very young adults: apropos four patients and a review of the literature. $J$ Cancer Res Clin Oncol. 2000;126(4):233-7.

Kong X, Wang JL, Chen HM, Fang JY. Comparison of the clinicopathological characteristics of young and elderly patients with gastric carcinoma: a meta-analysis. J Surg Oncol 2012; 106: 346-52.

Kuller LH. Age-adjusted death rates: a hazard to epidemiology? Ann Epidemiol 1999; 9(2):91-2.

Kunisaki C, Akiyama H, Nomura M, Matsuda G, Otsuka $\mathrm{Y}$, Ono $\mathrm{H}$, et al. Clinicopathological Features of Gastric Carcinoma in Younger and Middle-Aged Patients: A Comparative Study. J Gastrointest Surg 2006; 10(7):1023-32.

Liu S, Feng F, Xu G, Liu Z, Tian Y, Guo M, et al. Clinicopathological features and prognosis of gastric cancer in young patients. BMC Cancer 2016; 16:478.

Piazuelo MB, Correa P. Gastric Cancer: Overview. Colomb Med (Cali) 2013; 44:192-201.

Prochorov A, Labunec I, Kazakevich V, Shepetjko M, Papok V. Gastric Cancer in Young Patients Under The Age of 30 Years. J Cancer Sci Clin Oncol 2015; 1:1-4.

Saito H, Takaya S, Fukumoto Y, Osaki T, Tatebe S, Ikeguchi M. Clinicopathologic characteristics and prognosis of gastric cancer in young patients. Yonago Acta Med 2012; 55(3):57-61. 
Santoro R, Carboni F, Lepiane P, Ettorre GM, Santoro E. Clinicopathological features and prognosis of gastric cancer in young European adults. $\mathrm{Br} J$ Surg 2007; 94(6):737-42.

Takatsu Y, Hiki N, Nunobe S, Ohashi M, Honda M, Yamaguchi T, et al. Clinicopathological features of gastric cancer in young patients. Gastric Cancer 2015; 19(2):472-8.
Wakui S, Motohashi M, Muto T, Takahashi H, Hano $H$, Jutabha $P$, et al. Sex-Associated Difference in Estrogen Receptor $B$ Expression in N-MethylN'-Nitro-N-Nitrosoguanidine-Induced Gastric Cancers in Rats. Langenbeck's Arch Surg 2008; 393:37-43.

Wang Y, Lian B, Dong Y, Wang N, Yang W. Clinicpathological Features of Gastric Cancer in Young Patients. J Can Ther 2014; 5:1366-1371. 


\section{Egyptian Association for Cancer Research (EACR)}

http://eacr.tanta.edu.eg/

EACR is an NGO society that was declared by the Ministry of Social Solidarity (Egypt) No. 1938 in 19/11/2014 based on the initiative of Prof. Mohamed Labib Salem, the current Chairman of EACR. EACR aims primarily to assist researchers, in particular young researchers in the field of cancer research through workshops, seminars and conferences. Its first international annual conference entitled "Anti-Cancer Drug Discovery" was successfully organized in April 2019 (http://acdd.tanta.edu.eg). Additionally, EACR aims to raise the awareness of the society about the importance of scientific research in the field of cancer research in prediction, early diagnosis and treatment of cancer. EACR is also keen to outreach the scientific community with periodicals and news on cancer research including peer-reviewed scientific journals for the publication of cutting-edge research. The official scientific journal of EACR is "International Journal of Cancer and biomedical Research (IJCBR: https://jcbr.journals.ekb.eg) was successfully issued in 2017 and has been sponsored by the Egyptian Knowledge Bank (EKB: www.ekb.eg).

\section{EACR Chairman,}

Prof. Mohamed Labib Salem, PhD

Professor of Immunology

Faculty of Science, Tanta Universiy, Egypt 


\section{GUIDE FOR AUTHORS}

Publisher :The International Journal of Cancer and Biomedical Research (IJCBR) is an International and interdisciplinary journal of preclinical and clinical studies in the area of cancer and biomedical research. It is a peer-reviewed journal in English, published quarterly (in March, June, September, and December) by the Egyptian Association for Cancer Research (EACR) in both print and online formats (4 issues making a volume). Special issues or supplements may also be produced from time to time upon agreement with the Editorial Board.

Scope :The main aim of IJCBR is to attract the best research in animal and human biology in health and diseases from across the spectrum of the biomedical sciences at the molecular, cellular, organ, and whole animal levels especially those that are related to cancer research, including causes, prediction, diagnosis, prognosis, and therapy.

Publication Fees :The journal does charge for submission, processing, or publication of manuscripts (2000 LE for Egyptians or $250 \$$ for non-Egyptians; EACR members receive 15\% discount on publication). Of them Peer-review fees (300 LE) should be paid on submission (non-refundable). For the fast-track production of the accepted manuscript, another 500 LE is paid.

General specifications for different types of article

- Submitted manuscripts should not have been published previously, except in a limited form (e.g. short communication to a symposium or as part of MSc or PhD theses) and should not be under consideration for publication by other journals.

- All co-authors should agree with the content of the manuscript. Authors must have obtained permission to use any copyrighted material in the manuscript before submission.

IJCBR publishes different types of articles

- Original Article (6000 words with $\mathbf{4}$ tables and $\mathbf{4}$ figures, maximum $\mathbf{8}$ display items): Articles with novel findings are the target of IJCBR. Articles presenting a detailed description of a new technique, comparison of existing methods, meta-analyses with comprehensive and in-depth discussion are considered. Papers in a numbered series are not accepted unless all are submitted at the same time.

- Short communications or case study (3000 words with $\mathbf{4}$ display items): Short communications present exceptionally exciting, novel or timely contents are considered. They will be peer-reviewed in the same way as research papers. The references are restricted to 15 .

- Reviews or systematic review (9000 words with $\mathbf{1 0}$ display items): They are invited by the Editorial Board or unsolicited. Review articles have to be contemporary and comprehensive and add information to the knowledge. Sharp critical analyses of novel data or concepts are encouraged. When relevant, a statistical analysis of data and a meta-analysis approach are recommended.

- Opinion papers, letter to the editor or comment to the editor (1500 words with $\mathbf{2}$ display items): They are submitted by invitation of the Editorial Board. They are short papers, which aim to inform scientists, industry, and the public and policymakers about cutting-edge issues in research or the impact of research. They reflect the opinion of their authors who bear full responsibility of the published paper. The references are restricted to 10 .

- Conference/Symposium papers: The journal will consider for publication the results of original work and critical reviews that are presented at conferences/symposia. Symposium organizers who wish to publish bundles of papers from a symposium/conference in IJCBR should first contact the Editor-in-Chief of the IJCBR (EACR@unv.tanta.edu.eg) for agreement. Supplementary material can be proposed and will be made available online. The responsibility for the preparation of a paper in a form suitable for publication lies with the author.

- Thesis: IJCBR can publish the summary and abstract of Master and PhD theses in a special issue.

English: Good quality of written English is required. Spelling may be in British or American English but must be consistent throughout the paper. Care should be exercised in the use of biological terminology that is ill-defined or of local familiarity only. We recommend that authors have their manuscripts checked by an English language native speaker before submission.

Manuscript layout: Manuscripts should be prepared using a standard word processing program and presented in a clear readable format with easily identified sections and headings. The manuscript layout is based on the following directions.

- The main text contains Title, Abstract, Keywords, Introduction, Material and Methods, Results, Discussion, References, Tables, figures.

- The title needs to be concise and informative. Use bold, with an initial capital for the first word only and for words that ordinarily take capitals.

- Short (running) title (max 80 characters including spacing).

- The article text should be typed with double line spacing with wide margins $(2.5 \mathrm{~cm})$.

- The lines must be continuously numbered; the pages must also be numbered.

- Font Calibri 12 should be used for the text, and 12 for the tables, figure legends and references.

- The sections should typically be assembled in the following order:

- Title page contains title, authors' names, full affiliations, acknowledgements and the corresponding author's contacts and Short title.

Abstract (max 250 words, single paragraph): The abstract should be complete and understandable without citation, references, table, or figure. Use structured abstract: Background, Aim, Materials \& Methods, Results and Conclusion. The context and the rationale of the study are presented succinctly to support the objectives. The experimental methods and main results are summarized but should not be overburdened by numerical values or probability values. The abstract ends with a short and clear conclusion. 
Keywords: Up to five short and specific keywords should complement the title with respect to indicating the subject of the paper in alphabetic order.

Introduction: The introduction briefly outlines the context of the work, presents the current issues that the authors are addressing and the rationale to support the objectives, and clearly defines the objectives.

Material and methods: Material and methods should be described in sufficient details so that others can repeat the experiment. Reference to previously published work may be used to give methodological details, provided that said publications are readily accessible and in English. The code of ethics should be followed for all experiments use animals or human samples.

Statistical analysis of results: The statistical design and the models of statistical analysis must be described, as well as each of the statistical methods used. Sufficient statistical details must be given to allow replication of the statistical analysis. The experimental unit should be defined (e.g., individual or group of animals).

Results: Data are presented as tables and figures. Brief description of the results for each table and figure should be presented. Unpublished data can be mentioned when necessary.

Discussion: Should be separate from the Results section and should focus only on intra- and inter-data discussion (the data in the results section) as well as with the relative data in the literature. Don't repeat information already presented in the Introduction section. Start the first paragraph in the Discussion with a paragraph stating the rationale behind the study, the objectives, and the main findings. End Discussion with a short conclusion.

Acknowledgements: In this section, the authors may acknowledge (briefly) their support staff.

Conflict of interest: All papers with a potential conflict of interest must include a description/explanation in a separate heading.

Funding details: The authors should state the source of findings of the study (with research funder and/or grant number). If no fund, the authors should state that the study is self-funded.

\section{References}

Citation of references: In the text, references should be cited by the author(s) surname(s) and the year of publication (e.g. Salem, 2020). References with two authors should be cited with both surnames (e.g. Salem and Meshrif, 2021). References with three or more authors should be cited with the first author followed by et al. (in italics; e.g. Salem et al., 2021). Names of organizations used as authors (e.g. Food and Drug Administration) should be written out in full in the list of references and on the first mention in the text. Subsequent mentions may be abbreviated (e.g. FDA).

- List of references. Literature cited should be listed in alphabetical order by authors' names. It is the author's responsibility to ensure that all references are correct. All authors should be written and so the full journal name.

- $\quad$ References from journal articles are formatted in APA as this example: Al-Amoudi WM (2018). Toxic effects of Lambdacyhalothrin on the rat thyroid. Involvement of oxidative stress and ameliorative effect of ginger extract. Toxicology Reports, 5: 728-736.

- $\quad$ References from books or official reports are formatted as this example. Kebreab E, Dijkstra ANM, Bannink A, Gerrits WJJ, \& France J (2006). Nutrient digestion and utilization in farm animals. CABI Publishing. Wallingford, UK.

- References from chapters or parts of books are formatted as this example. Nozière $P, \&$ Hoch $T$ (2006). Modelling fluxes of volatile fatty acids from rumen to portal blood. In: Nutrient digestion and utilization in farm animals (Kebreab E, Dijkstra ANM, Bannink A, Gerrits WJJ \& France J, eds.), pp. 40-47. CABI Publishing. Wallingford, UK.

Tables: The data should be presented in tables or in graphs, not both.

- Each table should be placed on a separate page at the end of the main text.

- Tables are numbered consecutively using Arabic numbering. They are referred to as Table 1 , Table 2, etc., with capital ' $T$ ', no italics

- $\quad$ Each table has its explanatory caption. The caption is sufficient to permit the table to be understood without reference to the text.

- Abbreviations used in tables/figures have to be defined either as footnotes or in the caption.

\section{Figures}

- $\quad$ Package the figures in a single PowerPoint file. Each figure in a separate slide.

- Figure size should be readable in a width of approximately 8-175 $\mathrm{mm}$ (i.e. the maximum size of printing over two columns).

- Ensure that the font size is large enough to be readable at the final print size, use Calibri font to ensure that they are consistent throughout the figures.

- $\quad$ The figures should preferably be provided as TIFF or EPS files.

- The resolutions of figures must be at least $300 \mathrm{dpi}$.

- Preparation of images for a manuscript: For guidance, we refer to the Journal of Cell Biology's instructions to authors (http://jcb.rupress.org/site/misc/ifora.xhtml\#image_aquisition).

- If a cropped image is included in the main text of a paper (e.g. a few lanes of a gel), display the full original image, including the appropriate controls, the molecular size ladder and/or the scale as relevant, as a single figure in a Supplementary Material file to facilitate peer-review and for subsequent online publication.

- Supplementary material is submitted along with the main manuscript in a separate file and identified at uploading as "Supplementary File - for Online Publication Only" The title of the article is included at the top of the supplementary material.

Corresponding author's guidelines: Upon acceptance the corresponding author is required to send his/her recent formal photo to be attached to the front page of the article. 


\title{
International Journal of Cancer \& Biomedical Research
}

(IJCBR) Online ISSN 2682-2628

\author{
Editor-in-Chief \\ Mohamed Labib Salem, PhD \\ Tanta University, Egypt
}

\begin{tabular}{l} 
EACR Board \\
\hline Nehal Elmashad, MD \\
Tanta University, Egypt \\
Nabil Mohy Eldin, PhD \\
Kafrelsheikh University, Egypt \\
Doaa Al-Ghareeb, PhD \\
Alexandria University, Egypt \\
Abdel-Aziz Zidan, PhD \\
Damanhour University, Egypt
\end{tabular}

\begin{tabular}{l} 
Managing Editor \\
\hline Wesam Meshrif, PhD \\
Tanta University, Egypt \\
Sohaila Galal, PhD \\
Tanta University, Egypt \\
Production and Contact \\
\hline Hamdi Kandil \\
Tanta University, Egypt \\
Email: ljcbr100@gmail.com
\end{tabular}

\section{Advisory Board}

Alberto Montero, MD

Taussig Cancer Center, Cleveland,

USA

Yi Zhang, MD

Zhengzhou University, China

Mark Robunstein, Ph D

Medical University of South

Carolina, USA

Mohsen Farid, Ph D

Derby University, USA

Natarajan Muthusamy, Ph D

Ohio State University, USA

Hideki Kasuya, MD

Nagoya University, Japan

Sherif El-Khamisy, Ph D

Sheffield University, UK

Mohamed Ghanem, Ph D

Kafr Elshikh University, Egypt

Sayed Bakry, Ph D

Alazhar University, Egypt

Sameh Ali, Ph D

Nationa Liver Institute, Egypt

Gamal Badr, Ph D

Assuit University, Egypt

Nadia Hamdy, Pharm D

Ain Shams University, Egypt

\section{Editorial Board}

\section{Clinical studies}

Hesham Tawfik, MD

Tanta University, Egypt

Mohamed Attia, MD

Tanta University, Egypt

Mohamed Elshanshory, MD

Tanta University, Egypt

Essam Elshiekh, MD

Tanta Cancer Center, Egypt

Rasha Eraky, MD

Tanta University, Egypt

Shaima Abou-Kjatwa, MD

Tanta University, Egypt

Marcela Diaz, MD

Cleveland Clinic Foundation, USA

Mohamed Abou-El-Enein, MD

Charité Universitätsmedizin Berlin,

Germany
Alaa Eldin Almostafa, MD

McGill University, Canada

Olfat Gadallah, MD

Tanta University, Egypt

Nagla Sarhan, MD

Tanta University, Egypt

Naglaa Fathy, Pharm D

Zagazik University, Egypt

Mohamed Salama, MD

Mansoura University, Egypt

Mona Marie, MD

Alexandria University, Egypt

Preclinical studies

Mostafa El-Sheekh

Tanta University, Egypt

El-Refai Kenawy, Ph D

Tanta University, Egypt

Mohamed Noureldin, Ph D

Banaha University, Egypt

Yousry Albolkiny, Ph D

Tanta University, Egypt

Elsayed Salim, Ph D

Tanta University, Egypt

Shengdian Wang, Ph D

Chinese Academy of Sciences,

China

Sabry El Naggar, Ph D

Tnata Univesity, Egypr

Faris Alenzi, Ph D

Prince Sattam bin Abdulaziz

University, KSA

Ibrahim El-Sayed, Ph D

Menoufia University, Egypt

Tarek Aboul-Fadl, Ph D

Assiut University, Egypt

Rabab Khairat, Ph D

National Research Center,

Giza, Egypt

Wael Lotfy, Ph D

Alexandria University, Egypt

Ashraf Tabll, Ph D

National Research Center, Egypt

Nahla Shoukry, Ph D

Suez University, Egypt
Medhat Eldenary, Ph D

Tanta University, Egypt

Azza Hasan, Ph D

Menufia University, Egypt

Nanees Gamal Eldin, Ph D

Tanta University, Egypt

Mohamed Mansour, UK

Sabbah Hammoury, Ph D

Alexandria Ayadi Almostaqba

Oncology Hospital, Egypt

Nehal Aboulfotoh, Ph D

Zewail City for Science and

Technology, Cairo, Egypt

Amir Elkhami, Ph D

Galaxo, San Francisco, USA

Ahmed Alzohairy, Ph D

Zagazi University, Egypt

Wgady Khalil, Ph D

National Research Center, Egypt

Amr Amin, Ph D

United Arab Emirates

University, UAE

AbdelRahman Zekri, Ph D

National Cancer Institute, Egypt

Hussein Khamis, Ph D

Alexandria University, Egypt

Magdy Mahfouz, Ph D

Kafr Elsheikh University, Egypt

Ehab Elbedewey, Ph D

Tanta University, Egypt

Abeer Badr, Ph D

Cairo University, Egypt

Mamdooh Ghoneum, Ph D

Charles Drew University of

Medicine \& Science, USA

Haiam Abou Elela, Ph D

National Institute of Oceanography and Fisherie, Egypt

Maha EL-Demellawi, Ph D City for Scientific Research \&

Technology Applications, Egypt

Desouky Abd-El-Haleem, Ph D

City for Scientific Research \&

Technology Applications, Egypt 